Plant Tissue Cult. \& Biotech. 25(1): 51-62, 2015 (June)

$\overline{\text { PTC\&B }}$

\title{
Effect of Sugar Types, Culture Age, Concentrations of 2,4-D and Sucrose on Somatic Embryogenesis of Cymbopogon schoenanthus subsp. proximus
}

\author{
Asmaa M. Abdel-Salam ${ }^{1}$, Kamal Chowdhury ${ }^{*}$ and \\ Ahmed A. El-Bakry ${ }^{1}$ \\ Department of Biology, Claflin University, Orangeburg, SC 29115, USA \\ Key words: Cymbopogon schoenanthus subsp. proximus, Sugar types, Somatic \\ embryogenesis, Sucrose
}

\begin{abstract}
The effect of sugar types, age of culture, and concentrations of 2,4-D and sucrose on somatic embryogenesis was investigated in Cymbopogon schoenanthus subsp. proximus. Six different sugar types: sucrose, fructose, maltose, glucose, galactose and lactose at $3 \%$ concentration were used for each of three 2,4-D concentration treatments (1.0, 2.0, $4.0 \mathrm{mg} / \mathrm{l})$. ANOVA showed a significant difference at the $1 \%$ level for culture age, sugar types and interactions between 2,4-D and sugar types when mean embryo numbers of individual sugars across the four culture ages are compared. Maltose gave highest mean value, followed by sucrose and the lowest mean number was recorded with galactose. Cultures induced by galactose although low in embryo induction gave the highest mean number of shoots across the different media and culture age. Effect of different concentrations of sucrose and BA on production of number of immature somatic embryos, mature germinating somatic embryos and shoots was examined by culturing 2.5 month-old seed-derived callus onto MS medium containing 4 different sucrose concentrations $(1.0,2.0,3.0,4.0 \%)$ in combination with different BA concentrations $(0.0,0.025,0.05,0.1 \mathrm{mg} / \mathrm{l})$. ANOVA showed significant differences at $1 \%$ level for culture age, and interactions between culture age and sucrose concentrations. Mean number of shoots on $1 \%$ sucrose for 7 months old culture was 9.4 significantly higher than number produced on all of sucrose concentrations. The efficient regeneration system will be useful for the future production of high yielding genotypes and for the conservation of the species germplasm.
\end{abstract}

*Author for correspondence: <kamalc54@yahoo.com>; <ael_bakry@yahoo.com>. ${ }^{1}$ Department of Botany, Faculty of Science, Helwan University, Ain Helwan, Cairo 11795, Egypt. 


\section{Introduction}

Cymbopogon schoenanthus subsp. proximus, locally known as Halfa-barr, an aromatic densely-tufted grass, is a monocot plant belongs to Gramineae. The plant species grows in Upper Egypt, north of Sudan and south of Sahara from Mauritania to Ethiopia and Kenya (Boulos 1999). The herb is used extensively in folk medicine for many diseases such as influenza, some neurotic diseases, colic, fever, H-diabetes, as diuretic, stomachic, hypotensive, carminative, and antirheumatic (Boulos 1983). It is used as renal antispasmodic agent (EL-gamal et al. 1987), for relieving bronchial asthma, anti-hyperglycemic and alleviates liver and renal damage in rats (Sheweiata et al. 2002). The plant has antimicrobial and antifungal activities (Selim 2011). It also inhibits kidney stone formation (Ibrahim et al. 2013). It has shown antihypertensive activity in rats (Nezhawy 2014).

C. schoenanthus subsp. proximus has been shown to contain medicinally important compounds such as cryptomeridiol (Locksley et al. 1982), proximadiol, $5 \alpha$ - hydroxy- $\beta$-eudesmol, $1 \beta$-hydroxy- $\beta$-eudesmol, $1 \beta$ - hydroxy- $\alpha$-eudesmol, $5 \alpha$ hydroperoxy- $\beta$-eudesmol, $7 \alpha, 11$-dihydroxycadin-10-(14)-ene (EL-Askary et al. 2003). Due to its significant effect on expulsion of renal stones, the drug PROXIMOL (Halphabarol) has been produced from the wild plant (Ministry of Health, Egypt, product registration \# 24526). The production of the drugs is totally dependent on material collected from the wild. Overcollection of this subspecies for both folk uses and drug production, together with, the climate change make the species threatened and may ultimately lead to its extinction from the wild.

In authors' previous study (El-Bakry and Abdelsalam 2012), they reported a protocol for regeneration of this subspecies from callus and suspension cultures, where sucrose was the only carbon source. As sucrose is the main sugar translocated in the phloem of many plants, it is often assumed to be the best choice of carbon source in cell and tissue culture media (Peterson et al. 1999). However, there are a number of plants that can grow on carbohydrates other than sucrose, and sucrose may not be the most suitable carbohydrate for plant regeneration. Media containing glucose, fructose, maltose, mannose or sorbitol stimulated regeneration via somatic embryogenesis or organogenesis in a number of plants (Borkowska and Szczerba 1995, Bach and Pawowska 1993, Fuentes et al. 2000, Tang 2000, Blanc et al. 2002, El-Bakry 2002, Sairam et al. 2003, Trejgell et al. 2006 and Bahmani et al. 2009).

Gauchan (2012) investigated the effect of various concentrations of different sugars for induction of root and shoot from maize seeds. The seedling development was induced by the application of fructose, maltose and sucrose at seven different concentrations ranging from 0.25 and $10 \%$ ) of each. Of the three 
sugars tested, low concentrations $(0.25-2.5 \%)$ of maltose and sucrose exhibited the maximum shoot and root growth and the plantlets were healthy. In all the concentrations of maltose and sucrose, the growth response of both shoot and root was good.

As a part of authors continuing studies on C. schoenanthus subsp. proximus, they have investigated the effect of sugar types and their concentrations on somatic embryogenesis of this plant species. Application of these research results may help in both habitat restoration and selection of superior clones that can be further propagated in the future.

\section{Materials and Methods}

Inflorescences of Cymbopogon schoenanthus subsp. proximus were collected from Aswan University botanic garden, Egypt, and stored in paper bags at $25^{\circ} \mathrm{C}$. Seeds were separated from the inflorescence immediately before surface sterilization.

Healthy seeds were washed for 15 min under tap water and then rinsed with double distilled water. The seeds were then surface sterilized by dipping in $95 \%$ ethyl alcohol for $1 \mathrm{~min}$ followed by immersion in $20 \%$ Clorox $(5.25 \%$ sodium hypochlorite) for $20 \mathrm{~min}$. Thereafter, the seeds were washed three times with sterile distilled water under aseptic conditions.

Surface sterilized seeds were cultured on MS supplemented with 3 different concentrations of 2, 4-D (1.0, 2.0, $4.0 \mathrm{mg} / \mathrm{l})$ and $0.5 \mathrm{mg} / \mathrm{l} \mathrm{BA}(\mathrm{D} 2 \mathrm{~B} 2, \mathrm{D} 3 \mathrm{~B} 2$ and D4B2, respectively). Six different sugars: sucrose, fructose, maltose, glucose, galactose and lactose at 3\% concentration were used for each 2,4-D concentration treatments. For each treatment, 3 replication plates, 5 seeds/plate were carried out. First subculture was carried out onto the same media after 1.5 months. Second subculture was done after 3 months from the date of initial culture on media containing the same sugar type but with $1 / 4$ concentration of growth regulators. Third subculture was carried out after 4.5 months onto MS containing $0.01 \mathrm{mg} / \mathrm{l} \mathrm{BA}$ and $2 \%$ sucrose for all media. Six months old cultures were subcultured onto MS hormone free media with $2 \%$ sucrose for all sugar types. Five $\mathrm{ml}$ of MS hormone free liquid medium was added to each culture plate after 7.5 and 9 months.

Four weeks following the addtion of the first liquid media, the regenerated shoots were separated and transferred to the rooting medium (MS with $0.1 \mathrm{mg} / \mathrm{l}$ NAA and $15 \mathrm{~g} / \mathrm{l}$ sucrose). Well rooted plants were transferred to plastic pots containing sand and acclimatized to natural environment.

Sterile seeds were cultured on MS supplemented with $1.0 \mathrm{mg} / 1$ 2,4-D, 0.5 $\mathrm{mg} / \mathrm{l} \mathrm{BA}$ and $30 \mathrm{~g} / \mathrm{l}$ sucrose. The first subculture was made on the same medium 
after one month. The second subculture was made after 2.5 months onto MS supplemented with 4 different sucrose concentrations $(1.0,2.0,3.0,4.0 \%)$ in combination with different BA concentrations $(0.0,0.025,0.05,0.1 \mathrm{mg} / \mathrm{l})$. For each treatment 3 replication plates, 4 explants /plate were made.

The third subculture was made after 4 months onto MS hormone free medium supplemented with $0.1 \mathrm{~g} / \mathrm{l}$ glutamine and $3 \%$ sucrose. Five $\mathrm{ml} \mathrm{MS}$ hormone free liquid medium supplemented with $0.1 \mathrm{~g} / \mathrm{l}$ glutamine and $2 \%$ sucrose were added to each culture plate after 6 and 7 months.

After 7.5 months of initial culture, healthy shoots were transferred to the rooting medium (MS with $0.01 \mathrm{mg} / \mathrm{l} \mathrm{NAA}$ and $1.5 \%$ sucrose). Acclimation was carried out after 9.5 months.

All cultures were incubated at $25^{\circ} \mathrm{C}$ under cool white fluorescent light (3000 lux) for a light/dark photoperiod of $8 / 16 \mathrm{hrs}$ for the first 2.5 months of culture followed by $16 / 8 \mathrm{hrs}$ photoperiod till the end of the rooting stage.

From sugar type experiments, data were collected as number of somatic embryos, number of maturing embryos, and number of shoots from 4.5, 6, 7.5 and 9 months-old cultures.

From sugar concentrations experiments, data were collected as number of somatic embryos, number of maturing embryos with cotyledon, and number of shoots from 4, 6, and 7 months-old cultures.

Data were analyzed statistically by analysis of variance (ANOVA) from completely randomized design according to the procedure described by Snedecor and Cochran (1981). Duncan's multiple range test (Duncan 1955) was used to compare treatment means.

\section{Results and Discussion}

To test the effect of different sugar types, age of cultures and 2,4-D concentrations on production of somatic embryos, germinating embryos and shoots from cultures were studied. For somatic embryo production, data were collected from a total of 216 plates (6 sugar types $\times 4$ culture ages $\times 3$ concentrations of 2,4-D $\times$ three replications). ANOVA showed significant differences at $1 \%$ level for culture age, sugar types and interactions between 2,4$\mathrm{D}$ and sugar types (ANOVA table not shown). Media factors, as well as, other interactions were non-significant. For germinating embryo and shoot production, data were collected from a total of 108 plates (6 sugars $\times 2$ culture ages $\times 3$ concentrations of 2,4-D $\times$ three replications). For germinating embryo production, ANOVA showed significant differences at the $5 \%$ level for sugar types and interactions between 2,4-D and sugar types (ANOVA table not 
shown). Media factors, culture age and other interactions were non-significant. For shoot production, ANOVA showed significant difference at 1\% level for culture age, sugar types and interactions between 2,4-D and sugar types, and between culture ages and sugar types (ANOVA table not shown). Significant difference was at $5 \%$ level for interactions due to all three sources. Media factors, as well as, interactions between 2,4-D and culture ages were non-significant.

Mean number of somatic embryos and germinating maturing embryos after four different age of cultures, three 2,4-D concentrations in combination with different sugar types are shown in Table 1. Mean number of embryos for all six sugar types against age of cultures showed that early stages in culture gave a higher mean embryos number $(2,2.48)$ after $4.5,6$ months, respectively, than 9month-old cultures (1.04), with 7.5 month old culture giving highest mean of 4.5. However, when mean embryo numbers of individual sugars across the four different ages of culture ages are compared, maltose gave highest mean value (4.1) followed by sucrose (3.2), and the lower mean number was recorded with galactose (1.27). The results reported here suggest that the exploration of different sugar types of media containing different concentration of 2,4-D was a worthwhile investigation as sucrose, most commonly used as a carbon source for shoot production through somatic embryogenesis. Similar results of different somatic embryogenesis response by different carbon sources were reported by Trarone and Guitinan (2006) on cacao genotypes. Similar results of superiority of maltose over sucrose on somatic embryo production have been demonstrated in petunia (Raquin 1983), in alfalfa (Strickland et al. 1987), in pine (Nagmoni et al. 1983), in Coffea canephora (Fuentes et al. 2000) and pea (Loiseaui et al. 1995).

Maturing embryos did not appear until 7.5 months after culture initiation. Mean numbers of maturing embryos after 7.5 and 9 months were not significantly different (4.3 and 5.6, respectively). Maltose, glucose, and lactose gave means of 7.1, 6.1 and 5.3 higher than other sugar types (significantly different at $5 \%$ only). Media by sugar type interaction (significantly different at $5 \%$ ) was manifested on D2B2 with maltose giving 10.2, D3B2, where glucose gave 6.5 and D4B2 where lactose gave the 8.3 mean number of maturing embryos. The results reported here suggest that the exploration of different sugar types of media containing different concentration of 2,4-D was also a meaningful investigation for mature somatic embryo production. Similar result of the effectiveness of maltose over sucrose on mature somatic embryo production has been confirmed in pine ( $\mathrm{Li}$ et al. 1998).

Mean number of shoots for all media after 7.5 and 9 months was 4.55 and 0.33 , respectively (Table 1 ). Mean number of shoots were significantly higher in 7.5 month-old culture compared to 9 month-old culture. The culture induced by 
galactose although low in embryo induction gave the highest mean number of shoots across the different media and culture age (5.03). After 7.5 months in cultures, shoots produced from galactose induced media on D3B2 (Fig. 1) gave the highest mean number of 15.2 that was significantly higher than fructose induced on the same media (9.9 shoots), higher than lactose induced cultures on D2B2 (Table 2). Similar result of different shoot production response through somatic embryogenesis due to different types of sugar was reported in peas (Loiseau et al. 1995), in pine (Nagmani et al. 1993) and in alfalfa (Strickland et al. 1987). 2,4-D concentration in the medium also played important role in the number of shoot production, lower concentration such as $2 \mathrm{mg} / \mathrm{l}$ responded significantly better than $4 \mathrm{mg} / \mathrm{l}$ in both 7.5 and 9 month-old cultures.

Table 1. Mean number of shoots after 7.5 and 9 months on different media D4B2, D3B2 and D2B2 in combination with different sugar types at $3 \%$ concentration. Means with same alphabet are not significantly different.

\begin{tabular}{lllllll}
\hline Culture age (month) & \multicolumn{3}{c}{7.5} & & \multicolumn{3}{c}{9.0} \\
\hline Sugar type & D2B2 & D3B2 & D4B2 & D2B2 & D3B2 & D4B2 \\
Sucrose & $0.11 \mathrm{ef}$ & $0.06 \mathrm{f}$ & $0.00 \mathrm{f}$ & $5.41 \mathrm{bcdef}$ & $0.00 \mathrm{f}$ & $0.00 \mathrm{f}$ \\
Fructose & $0.00 \mathrm{f}$ & $0.00 \mathrm{f}$ & $0.44 \mathrm{ef}$ & $3.05 \mathrm{def}$ & $9.91 \mathrm{~b}$ & $4.22 \mathrm{bcdef}$ \\
Maltose & $2.44 \mathrm{def}$ & $0.00 \mathrm{f}$ & $0.53 \mathrm{ef}$ & $7.88 \mathrm{bcd}$ & $0.99 \mathrm{ef}$ & $0.33 \mathrm{ef}$ \\
Glucose & $0.41 \mathrm{ef}$ & $0.00 \mathrm{f}$ & $0.00 \mathrm{f}$ & $2.85 \mathrm{def}$ & $6.16 \mathrm{bcde}$ & $0.00 \mathrm{f}$ \\
Galactose & $0.73 \mathrm{ef}$ & $0.73 \mathrm{ef}$ & $0.00 \mathrm{f}$ & $4.71 \mathrm{bcdef}$ & $15.18 \mathrm{a}$ & $8.86 \mathrm{bc}$ \\
Lactose & $0.44 \mathrm{ef}$ & $0.00 \mathrm{f}$ & $0.00 \mathrm{f}$ & $8.94 \mathrm{bc}$ & $0.00 \mathrm{f}$ & $3.55 \mathrm{cdef}$ \\
$\begin{array}{l}\text { Mean \# of shoots per } \\
\text { Medium }\end{array}$ & $0.69 \mathrm{c}$ & $0.13 \mathrm{~d}$ & $0.16 \mathrm{~d}$ & $5.47 \mathrm{a}$ & $5.36 \mathrm{a}$ & $2.83 \mathrm{~b}$ \\
$\begin{array}{l}\text { Mean \# of shoots per } \\
\text { culture age }\end{array}$ & & & & & & \\
\hline
\end{tabular}

The effect of different concentrations of sucrose was studied by transferring callus onto MS supplemented with 4 different sucrose concentrations (1.0, 2.0, 3.0, $4.0 \%$ ) with different BA concentrations $(0.0,0.025,0.05,0.1 \mathrm{mg} / \mathrm{l})$ followed by subculture onto hormone free medium with fixed sucrose concentration.

To test the effect of culture ages and concentrations of sucrose and BA on production of somatic embryo, germinating embryo and shoots from cultures, data were collected from a total of 144 plates $(3$ culture ages $\times 4$ concentrations of sucrose $\times 4$ concentrations of BA $\times$ three replications) for somatic embryo production. ANOVA showed significant differences at $1 \%$ level for culture age, and interactions between culture age and sucrose concentrations (ANOVA table 
not shown). Differences in concentration of sucrose and BA, and other interactions were non-significant. For germinating embryo and shoot production study, data were collected from a total of 96 plates ( 2 culture ages $\times 4$ concentrations of sucrose $\times 4$ concentrations of BA $\times$ three replications). For germinating embryo production, ANOVA showed a significant difference at $5 \%$
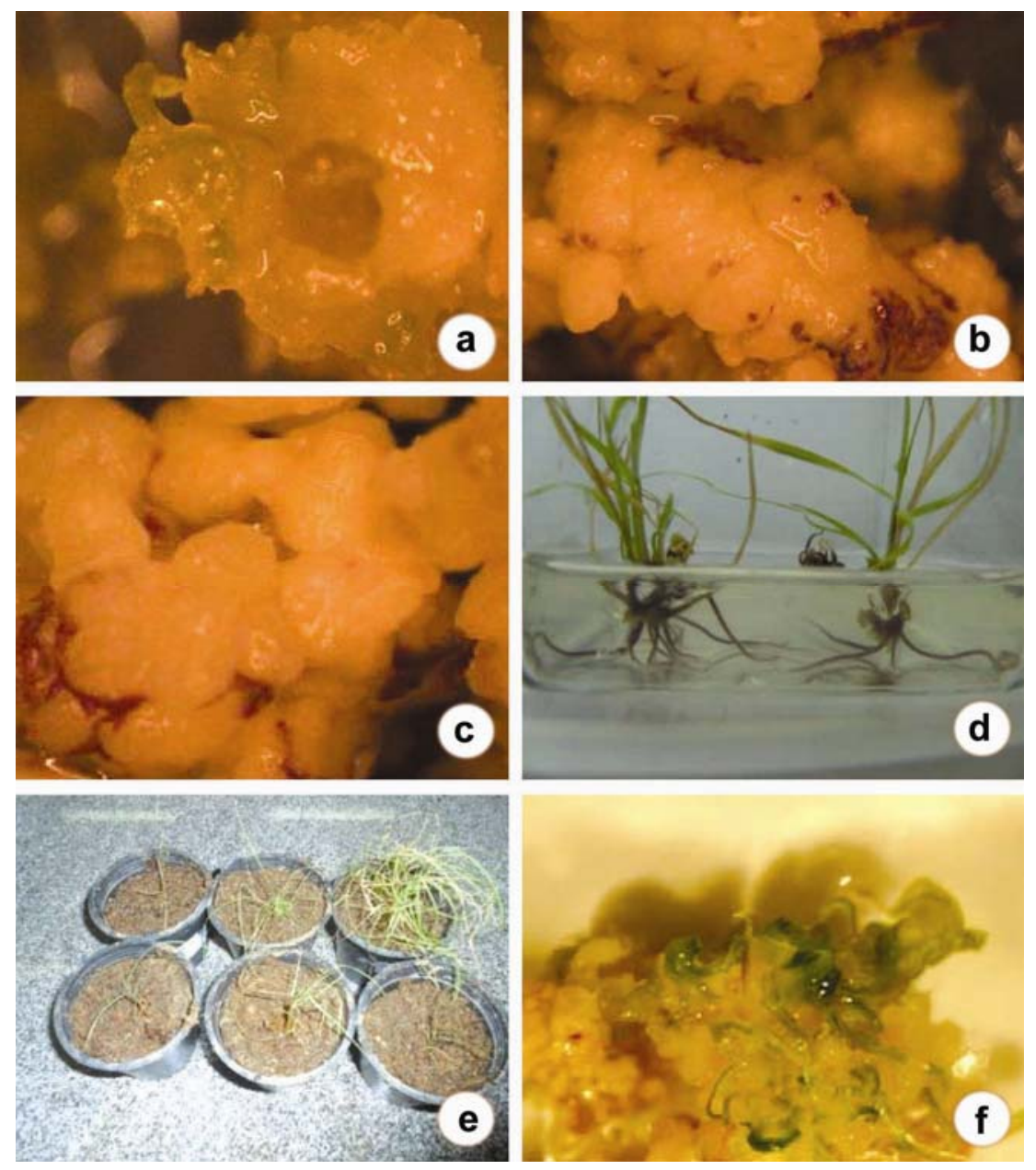

Fig 1. Regeneration of C. schoenanthus subsp. proximus through somatic embryogenesis induced on MS containing galactose. Embryogenic callus (a), callus with somatic embryos (b), mature embryos (c), germinating embryos (d), rooted plants (e) and acclimated plants (f).

level for culture ages and interactions between culture age and sucrose concentrations (ANOVA table not shown). Differences in the concentrations of sucrose and BA, and other interactions were non-significant. For shoot production, ANOVA showed significant differences at the $1 \%$ level for culture age, sucrose concentrations and interactions between culture age and sucrose 
concentrations (ANOVA table not shown). All other treatments and interaction tested were non-significant.

Since different concentrations of BA tested in this investigation did not show significant differences for the production of embryos, mature embryos or shoots, pooled data from all four BA concentrations are presented in Table 3. Embryo induction and growth in early stages (4 months) was best on higher sucrose concentrations of 3 and $4 \%$ giving mean embryo numbers of 3.3, 2.8, respectively. Six months old culture gave highest mean number across the culture period of 7.1 that was significantly higher than that of from either four months or seven months (Table 3). Mature embryos were high (8.2) on 3\% sucrose at 6 months, but higher (11.2) on $1 \%$ sucrose at 7 months (Table 3). Similar results of different induction response due to different sugar concentrations were reported by Bahmani et al. 2009, Yang et al. (2004) and Thomas (2006).

Germinating embryos, as measured by the number of healthy green growing shoots was low (0.07) after 6 months, but significantly higher (4.1) after 7 months. Mean number of shoots on $1 \%$ sucrose for 7 months old culture was 9.4 significantly higher than the germplasm of the number of species produced on all of sucrose concentrations (Table 3). Similar results of different regeneration response were reported by Anwar et al. 2005 and Abdullah et al. 2013.

Table 3. Mean comparison for number of embryos, mature embryos and shoot produced on MS containing different concentrations of sucrose BA concentrations pooled. Means with same alphabet are not significantly different.

\begin{tabular}{|c|c|c|c|c|c|c|}
\hline Source & $\begin{array}{c}\text { Culture age } \\
\text { (months) }\end{array}$ & $\begin{array}{l}\text { Sucrose } \\
(1 \%)\end{array}$ & $\begin{array}{l}\text { Sucrose } \\
(2 \%)\end{array}$ & $\begin{array}{l}\text { Sucrose } \\
(3 \%)\end{array}$ & $\begin{array}{l}\text { Sucrose } \\
(4 \%)\end{array}$ & Mean \\
\hline \multirow[t]{3}{*}{ Embryo } & 4 & $0.88 \mathrm{~d}$ & $1.45 \mathrm{~d}$ & $3.33 \mathrm{~cd}$ & $2.88 \mathrm{~cd}$ & $2.1 b$ \\
\hline & 6 & $9.06 \mathrm{a}$ & $6.86 \mathrm{ab}$ & $8.00 \mathrm{a}$ & $4.60 \mathrm{bc}$ & $7.1 \mathrm{a}$ \\
\hline & 7 & $2.81 \mathrm{~cd}$ & $2.95 \mathrm{~cd}$ & $1.85 \mathrm{~cd}$ & $1.00 \mathrm{~d}$ & $2.1 b$ \\
\hline \multirow[t]{2}{*}{ Mature embryo } & 6 & $2.70 c$ & $5.09 \mathrm{bc}$ & $8.25 a b$ & $5.15 b c$ & $5.3 b$ \\
\hline & 7 & $11.18 \mathrm{a}$ & $6.59 b c$ & $7.43 a b$ & $4.39 \mathrm{bc}$ & $7.4 \mathrm{a}$ \\
\hline \multirow[t]{2}{*}{ Shoots } & 6 & $0.10 \mathrm{~b}$ & $0.04 b$ & $0.04 b$ & $0.08 b$ & $0.07 \mathrm{~b}$ \\
\hline & 7 & $9.43 a$ & $3.06 b$ & $1.83 b$ & $2.1 b$ & $4.1 \mathrm{a}$ \\
\hline
\end{tabular}

Regeneration systems will be of high importance in conserving the germplasm of this species and producing new genotypes of high yields of bioactive compounds. The use of different types and concentrations of sugars in culture may also yield novel compounds or higher concentrations of already known medicinal compounds. Metabolic profiling of tissues and regenerated 
plants will produce valuable information from such systems, in particular when compared to the wild genotypes.

\section{Acknowledgements}

Part of the research reported was funded through grant \#79 from the Egyptian Academy of Scientific Research and Technology, Plant Biotechnology and Genetic Engineering program, to whom the authors are grateful.

\section{References}

Abdullah GR, Al-Khateeb AA and LaureneLayous LN (2013) Response of the strawberry cv. "Elsanta". Micro Propagation in vitro to different carbon sources and concentrations. Jordan J. Agril. Sci. 9(1): 1-10.

Anwar HM, Taslim HM, Raihanali M and Rahman MSM (2005) Effect of different carbon sources on in vitro regeneration of Indian Penny wort (Centella asiatica L.). Pak. J. Biol. Sci. 8(7): 963-965.

Bach A and Pawowska B (1993) Effect of type of carbohydrates in regulation of Hyacinthus orientalis L. in long-term cultures. Folia Horti. 2: 3-11.

Bahmani R, Karami O and Gholami M (2009) Influence of carbon sources and their concentrations on rooting and hyperhydricity of apple rootstock MM. 106. World App. Sci. J. 6(11): 1513-1517.

Blanc G, Lardet L, Martin A, Jacob JL and Carron MP (2002) Differential carbohydrate metabolism conducts morphogenesis in embryogenic callus of Havea brasiliensis (Müll. Arg.). J. Exp. Botany 53: 1453 -1462.

Borkowska B and Szczerba J (1995) Influence of different carbon sources on invertase activity and growth of sour cherry (Prunus cerasus L.) shoot cultures. J. Exp. Bot. 42: 911-915.

Boulos L (1983) Medicinal Plants of North Africa. Reference Publication Inc. Michigan, USA. p. 92.

Boulos L (1999) Flora of Egypt. Al Hadara publishing, Cairo, Egypt 1: 291-301.

Duncan DB (1955) Multiple ranges of multiple F tests. Biometrics 11: 1-42.

El-Askary HI, Meselhy MR and Galal AM (2003) Sesquiterpenes from Cymbopogon proximus. Molecules 8: 670-677.

El-Bakry AA (2002) Effect of genotype, growth regulators, carbon source, and $\mathrm{pH}$ on shoot induction and plant regeneration in tomato. In Vitro Cell. Dev. Biol. - Plant 38: 501-507.

El-Bakry AA and Abdel-Salam AM (2012) Regeneration from embryogenic callus and suspension cultures of the wild medicinal plant Cymbopogon schoenanthus. African J. Biotechnol. 11(34): 10098-10107.

Elgamal MH and Wolff $\mathbf{P}$ (1987). A further contribution to the sesquiterpenoid constituents of Cymbopogon proximus. Planta Medica 53(3): 293-294. 
El-Nezhawya AOH, Maghrabic IA, Mohamed KM and Omarf HA (2014) Cymbopogon proximus extract decreases L-NAME-induced hypertension in rats. Int. J. Pharm. Sci. Rev. Res. 27(1): 66-69.

Fuentes SRL, Calheiros MBP, Manetti-Filho J and Vieira LGE (2000) The effects of silver nitrate and different carbohydrate sources on somatic embryogenesis in Coffea canephora. Plant Cell Tiss. Org. Cult. 60: 5-13

Gauchan DP (2012) Effect of different sugars on shoot regeneration of maize (Zea mays L.). Kathmandu Univ. J. Sci. Engg. and Technol. 8(I): 119-124.

Ibrahim FA and El-Khateeb AY (2013) Effect of herbal beverages of Foeniculum vulgare and Cymbopogon proximus on inhibition of calcium oxalate renal crystals formation in rats. Annals Agril. Sci. 58(2): 221-229.

Li XY, Huang FH, Murphy BJ and Gbur EE (1998) Polyethylene glycol and maltose enhance embryo maturation in loblolly pine (Pinus taeda L.). In vitro Cell. Dev. Biol. Plant 34: 22-26.

Locksley HD, Fayez MBE, Radwan AS, Chari VM, Cordell GA and Wagner H (1982) Constituents of local plants XXV, Constitution of the antispasmodic principle of Cymbopogon proximus. Planta Medica 45: 20.

Loiseau J, Marche C and Deaunff YL (1995) Effects of auxins, cytokinins, carbohydrates and and amino acids on somatic embryogenesis induction from shoot apices of pea. Plant Cell Tiss. Org. Cult. 41: 267-272.

Nagmani R, Diner AM and Sharma GC (1993) Somatic embryogenesis in longleaf pine (Pinus palustris). Can J For. Research 23: 873-876.

Peterson KK, Hansen J and Krogstrup P (1999) Significance of different carbon source and sterilization methods on callus induction and plant regeneration of Miscanthus $\mathrm{x}$ ogiformis Honda 'Giganteus'. Plant Cell Tiss. Org. Cult. 58: 189-197.

Raquin C (1983) Utilization of different sugars as carbon source for in vitro anther culture of Petunia. Z. Pflanzenphysiol. 111: 453-457.

Sairam RV, Franclin G, Hassel R, Smith B, Meeker K, Kashikar N, Parani M, Abes DA, Ismail S, Berry K and Goldman SL (2003) A study on the effect of genotypes, plant growth regulators and sugars in promoting plant regeneration via organogenesis from soybean cotyledonary nodal callus. Plant Cell Tiss. Org. Cult. 75: 79-85.

Sheweita SA, Newairy AA, Mansour HA and Yousef MI (2002). Effect of some hypoglycemic herbs on the activity of phase I and II drug metabolizing enzymes in alloxan-induced diabetic rats. Toxicol. 2: 131-139.

Snedecor GW and Cochran WG (1981) Statistical Methods 7. The Iowa state Univ. Press, Ames, Iowa, U.S.A.soybean cotyledonary nodal callus. Plant Cell Tiss. Org. Cult. 75: 79-85.

Strickland SG, Nichol JW, McCall CM and Stuart AD (1987) Effect of carbohydrate source on alfalfa somatic embryogenesis. Plant Sci. 48: 113-121.

Tang W (2000) High frequency plant regeneration via somatic embryogenesis and organogenesis and in vitro flowering of regenerated plantlets in Panax ginseng. Plant Cell Rep. 19: 727-732. 
Thomas DT (2006) Effect of sugars, gibberellic acid and abscisic acid on somatic embryogenesis in Tylophora indica (Burm. f.) Merrill. Sheng Wu Gong Cheng Xue Bao. 22(3): 465-71.

Trejgel A, Magdalena Jarkiewicz and Andrzej Tretyn (2006). The effect of carbon source on callus induction and regeneration ability in Pharbitis nil. Acta Physiologiae Plantarum 28(6): 619-626.

Trerore A and Guiltinan MJ (2006) Effect of carbon source explants type on somatic embryogenesis of four cacao genotypes. Hortscience 41(3): 753-758.

Yang Z, Zhang L, Diao F, Huang M and Wu N (2004). Sucrose regulates elongation of carrot somatic embryo radicals as a signal molecule. Plant Mol Biol. 54(3): 441-59. 